\title{
THE NATURE OF FIBROSITIS \\ III. MULTIPLE LESIONS AND THE NEURAL HYPOTHESIS*
}

BY

\author{
MICHAEL KELLY
}

Department of Anatomy, University of Melbourne, Australia

Essential to the view of fibrositis presented in this and in the preceding two papers (Kelly, 1945, 1946) is the concept of the deep pain system. Sir James Mackenzie (1920), whose views upon pain-spread have been supported and amplified by the most recent advances, was not in possession of the knowledge which separates the cutaneous from the deep pain system. But-he asserted repeatedly that, when pain is referred from a viscus to the abdominal wall, deep rather than superficial hyperalgesia is likely to result. Lewis and Kellgren (1939) were the first to demonstrate that the two pain systems are anatomically separate; though Head, Rivers, and Sherren (1905) had pointed out that the paths which conveyed deep pressure-pain travelled with the motor nerves.

Clinically, there is a great deal of evidence suggesting such a functional division. Thus, pressurepain normally is not abolished by section of a sensory nerve (Trotter and Davies, 1909; SharpeySchäfer, 1927; Seddon, 1943). When anaesthesia

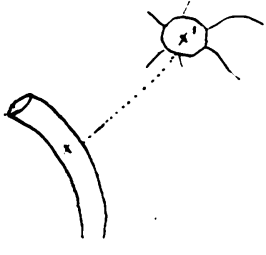

A

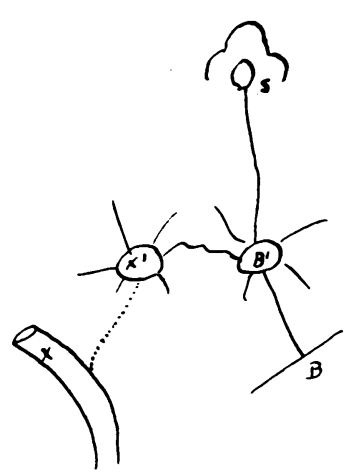

$A^{\prime}$
FIG. 1.-(After Mackenzie, Symptoms and Their Interpretation.)

A.- " The normal movements of a viscus, $X$, pass into tion."

$\mathrm{A}^{\mathrm{i}}$.-." Shows the mechanism of a viscerosensory reflex. A stimulus arising in a diseased organ, $X$ (as in gastric ulcer), passes into the central nervous system, $\mathrm{X}^{\prime}$, and if the stimulus be of a particular quality or strength it will affect a neighbouring sensory cell, $\mathbf{B}^{\prime}$, will be recognized as pain, and referred to the peripheral distribution of the nerve at $B$."

* Financial assistance from the National Health and Medical Research Council of Australia is gratefully acknowledged.

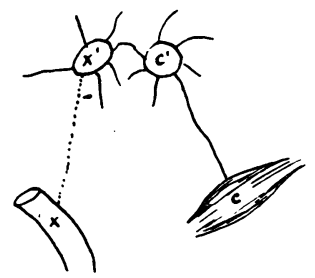

A

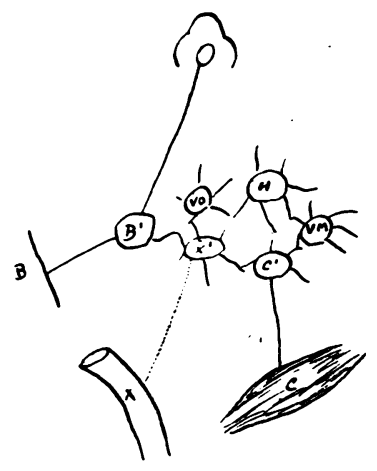

$A^{\prime}$
Fig. 2.- (After Mackenzie.)

A.- "Shows the mechanism of the viscero-motor reflex. A stimulus arising in a diseased organ, $X$, passes into the central nervous system, $X^{\prime}$, and affects a neighbouring, cell, $C^{\prime}$, which causes a contraction of skeletal muscle."

$\mathbf{A}^{\mathbf{1}}$.- " Illustrates the mechanism of multiple reflexes produced by visceral stimulation. An adequate stimulus arising in an organ, $X$, passes to $X^{\prime}$ in the central nervous system and affects a series of neighbouring cells, thus giving rise to pain (by stimulating $B^{\prime}$ ), muscle contraction (by stimulating $C^{\prime}$ ), vomiting (by stimulating the centre for vomiting, VO), cardiac depression (by stimulating the vagus, $H$ ), pallor and sweating (by stimulating the vaso-motor centres, VM)."

occurs in interstitial neuritis, the deeper tissues usually present normal or even enhanced sensitivity to pressure; this phenomenon is characterized by the term "anaesthesia dolorosa". There is much in Head's differentiation of protopathic from epicritic sensation which suggests that he was groping towards this more fundamental division.

\section{Myalgic Lesions and Visceral Disease}

In the second essay of this series, the development of a myalgic lesion from visceral disease was traced. The first step was the appearance of secondary or referred deep tenderness; and a spot in this affected area later became an autonomous lesion with its own secondary effects. The late Sir Thomas Lewis (1942) insisted that the mechanism of referred pain from somatic lesions did not differ from that of visceral referred pain; and so it was suggested that the same mechanism was employed when a fibrositic lesion formed in response to injury to somatic tissues.

Mackenzie's concept of the irritable focus in the cord was an accurate one, in that the spread of pain 
depends upon an area of heightened reflex activity; but he was not aware of the part played by reflex antidromic activity. Thus he suggested that tenderness in response to visceral disease was more apparent than real, normal impulses being modified while en route to the cerebrum because they had to pass through the irritable focus (see Fig. 1). The muscular rigidity he held to be the result of a true reflex (see Fig. 2), as were the numerous concomitants of severe visceral pain. "The hypersensitive or hyper-irritable focus of Mackenzie", wrote Hinsey and Phillips (1940), " takes on real meaning

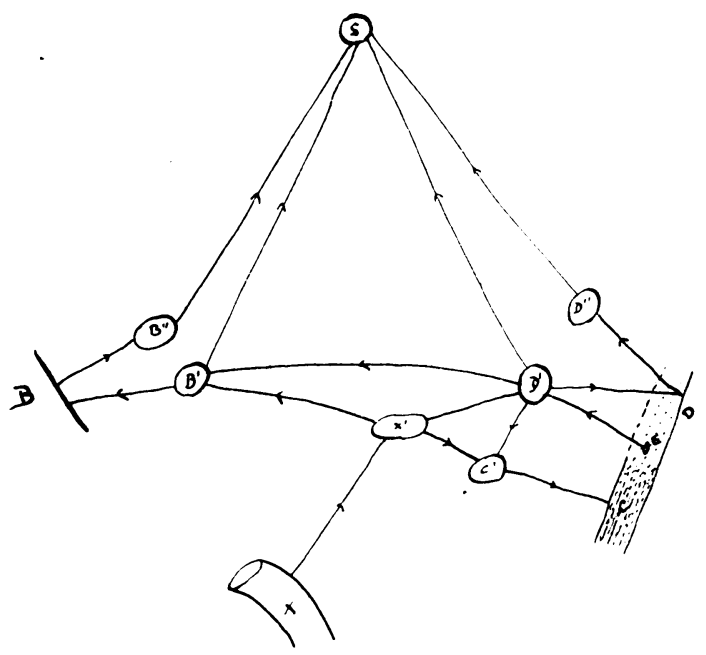

Fig. 3.-Illustrates, in the manner of Mackenzie, the present conception of the mechanism of the reflex spread of deep sensory and motor effects from a diseased viscus or from a myalgic lesion.

(1) The stimulus from $X$ passes to $X^{\prime}$, and, if adequate, stimulates a cell of deep pain sensation, $D^{\prime}$, a motor cell, $\mathrm{C}^{\prime}$, and, less commonly, a cell of cutaneous sensation, $B^{\prime}$. Antidromic impulses travel from $D^{\prime}$ to $D$, where the deep pain receptors are situated, and deep pain and hyperalgesia result, which are transmitted to a second deep sensory cell, D". Impulses from both $D^{\prime}$ and $D^{\prime \prime}$ are recorde dat $S$ as deep pain. Similarly, antidromic impulses from $B^{\prime}$ activate pain receptors in the skin and give rise to cutaneous hyperalgesia and pain which are transmitted to a second sensory cell, $\mathbf{B}^{\prime \prime}$. Impulses from $B^{\prime}$ and $B^{\prime \prime}$ are recorded at $S$ as cutaneous pain. A spot, $E$, in the hyperalgesic deep tissues, becomes acutely tender and gives off painful impulses on its own account, the resultant symptoms closely resembling those of the visceral disease.

(2) Eliminating $X$ and $X^{\prime}$, the diagram illustrates how a myalgic lesion, $E$, may give rise: (i) to diffuse deep tenderness: $E$ to $\mathrm{D}^{\prime}$ to $\mathrm{D}^{\prime}$ to $\mathrm{D}^{\prime \prime}$ to $\mathrm{S}$; (ii) to muscular rigidity: $E$ to $D^{\prime}$ to $C^{\prime}$ to $C$; (iii) to cutaneous hyperalgesia: $E$ to $D^{\prime}$ to $B^{\prime}$, etc.

if we assume that both somatic and visceral afferent fibres carry impulses which affect a common pool of secondary neurones and that the principle of summation and inhibition are applicable." Add to this the concept of the bi-directional conduction of impulses, which was not accepted in Mackenzie's day; impulses normally travel " antidromically" in sensory nerves, and an excess of reflex antidromic stimulation may be responsible for many of the painful manifestations of disease.

The tenderness in the abdominal wall, therefore, signifies a true physical change resulting from reflex stimulation through deep sensory neurones, and the state of affairs can be depicted as in Fig. 3. The reflex possesses an efferent arc even as the motor reflex does, and a relay through a second deep sensory neurone is necessary in order to transmit the sensation of tenderness to the cerebrum. In Fig. 3 is portrayed also the reflex production of muscular rigidity and cutaneous hyperalgesia, and a possible version of the manner in which a myalgic lesion arises. A part of the muscle (perhaps related to the muscular sense organs) may develop the features of a myalgic lesion, with the capacity to produce reflex secondary effects. After the cure of the visceral disease this lesion may endure, producing signs and symptoms resembling those of the disordered viscus.

\section{Spread from Injured Somatic Tissues}

When the formation of a myalgic lesion follows an injury, the process is analogous. The lesions show a tendency, as though under the influence of some unknown law, to develop in certain " sites of election ", which often are in the region of musculotendinous junctions. So frequently does this happen that it must be assumed that these sites have some functional connexion with the central nervous system. In Fig. 4 is attempted the portrayal of the development, in response to an injury to a digit, of a myalgic lesion in the upper part of the forearm, which causes a secondary radiation of pain back to the extremity (see Cases 10 and 15, Paper II).

1 A number of these "sites of election" are scattered through the somatic tissues, and they seem to have a strange affinity with the painful sequelae of injury, and indeed with all fibrositic processes (see Fig. 1 and the accompanying table in Paper II, 1946). When somatic pain begins to spread, it is as the result of heightened reflex activity in the cord, or the facilitation of nervous pathways; and a number of common sites may be involved together or in succession. At each of these sites the lesion

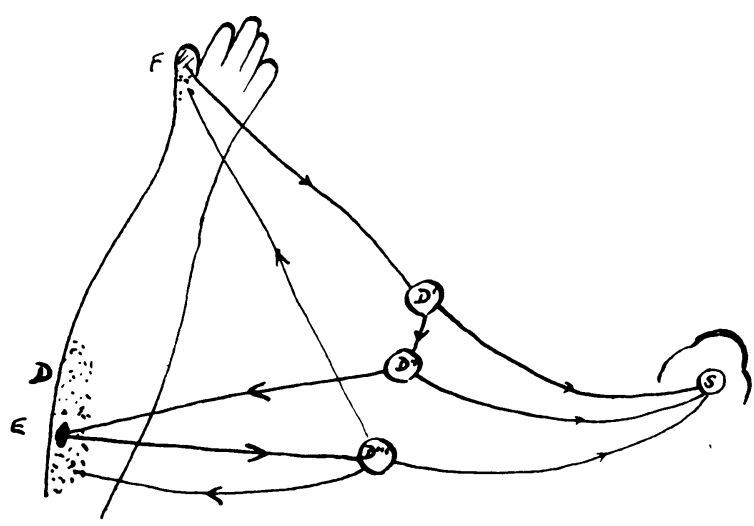

FIG. 4.-An injury to a digit, $F$, gives rise to stimuli which pass to a sensory cell, $D^{\prime}$. 'If the stimuli are adequate, a second sensory cell, $\dot{D}^{\prime \prime}$, is involved, which sends antidromic impulses to a " site of election," $E$. The resultant myalgic lesion establishes connexion with a third cell, D"', which by antidromic stimulation causes diffuse deep tenderness, D, and stimulates pain receptors at $F$, the site of the original injury. When the wound at $F$ heals, the persistence of the lesion, $E$, results in the persistence of pain and tenderness at $D$ and $F$. 
will produce its characteristic secondary effects (muscular stiffness, diffuse tenderness, pain radiating to joints, etc.). Fig. 5 suggests a possible mechanism by means of which this spread takes place.

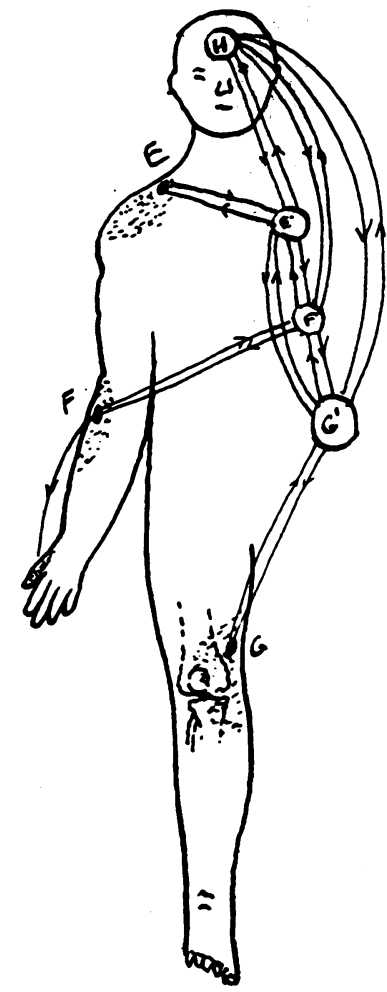

FIG. 5.-Illustrates the spread of the rheumatic process through a pool of sensory neurones. The sites of election, E F, G, appear to have special functional relations with groups of internuncial sensory cells, $E^{\prime}, F^{\prime}, G^{\prime}$. These groups are linked with each other and with higher centres $(\mathrm{H})$. Heightened reflex activity anywhere in this pool of neurones is capable of causing antidromic stimulation of $E, F, G$, with resultant local secondary effects (peri-arthritis of shoulder, pain referred to hand, synovitis of knee). Also, disordered activity of higher centres, $\mathrm{H}$, may lead in similar fashion to somatic manifestations.

$$
\text { difficult to explain }
$$

except as the effects of reflexes set off by the trigger mechanism of the injury. It is customary to assume the existence of an inherent predisposition to rheumatism. Douthwaite (1945) has quoted Ryden, who reported 19 cases in which rheumatic polyarthritis followed an injury to a single joint. In some of the cases reported by Ernstene and Kinell (1940), coronary occlusion was followed by periarthritis of the left shoulder, and later by rheumatoid changes in many joints.

\section{Case Reports}

$$
\text { CASE } 1
$$

Lumbar backache and "sciatic" pain following traumatic Achilles bursitis.-The rubbing of his boot caused a soldier's left heel to become painful. Four weeks later his back began to ache, and two weeks after this he felt a pain in the buttock which would radiate down the back of the thigh. Examination revealed a swelling at the insertion of the tendo calcaneus; there was also (1) a myalgic lesion in the left erector spinae muscle at the level of the fourth lumbar vertebra which caused painful limitation of flexion of the lumbar spine; (2) a lesion near the centre of the left gluteus maximus, with painful spasm of the hamstrings on straight-legraising. An injection of procaine into each lesion completely relieved both disabilities. Though the backache recurred, the "sciatica" did not return.

\section{CASE 2}

Multiple fibrositic lesions after injury to knee.-Gnr. T. R. had his right medial meniscus removed in Sept., 1940 , following an injury to the knee earlier in the year. The knee remained painful, and the pain later extended to the hip. In Feb., 1942, he complained, in addition, of (1) " sciatica " of six months' duration (pain in the right buttock would shoot down to the popliteal space and to the calf), and (2) a pain in his right shoulder, of three months' duration, made worse by moving his neck or abducting his humerus. On examination of the leg, pain was felt in the thigh and calf on attempting straight-legraising, but there was no cutaneous sensory abnormality or diminution of the ankle-jerk. A tender spot was found in the hamstring muscles 4 inches below the tuber ischii; deep infiltration with procaine completely abolished the disability; but it recurred when the analgesia passed off. The shoulder, however, was treated with complete success by the injection of a few c.cm. into a " supraspinous spot".

\section{Bilateral Symmetry}

To Sir James Paget (1879) the exact symmetry of many rheumatic lesions offered proof of the existence of a neural mechanism. "It is clearly", he wrote, " more probable that the symmetrical distribution of diseases on corresponding portions of the upperand lower extremities should depend on central nervous relations rather than on any assumed identity of chemical constitution." Livingston (1943) wondered at the paucity of medical comment on this frequently observed phenomenon.

When the present writer had produced in himself a painful artificial lesion of the muscles of the right calf (see Paper I), pain and deep tenderness extended up into the thigh and down to the commencement of the tendo calcaneus. On the following morning a pale reflection of the pain was felt in exactly corresponding regions of the left leg, and these areas were tender to pressure. Some weeks later, the left biceps brachii was treated in the same way, and on the following day both arms ached in regions which corresponded exactly. Two weeks after this, when another lesion had been produced in the left gastrocnemius, the right arm was painful and tender for a few hours in the identical region to which the pain previously had radiated from the left biceps. If this last observation has any significance, it suggests that the paths through which pain impulses must travel are subject to facilitation; and also that the impulses frequently do not confine themselves to the segments in which they originated. 
In Case 9 (Paper II), long-standing pain in both hands was cured by means of an injection of procaine into the left forearm. The following case is representative of a number in this series.

\section{CASE 3}

A soldier gave a history that in a cycle accident six years previously he had injured the knuckle of the right third metacarpal bone. There was no disability; but five years later he began to suffer intermittently from an aching pain in the metacarpo-phalangeal joint. When seen by the writer he had " reported sick", with a painful swelling of the third metacarpo-phalangeal joint of each hand. There was no radiological abnormality, and the disability subsided within ten days.

\section{Fibrositis and Febrile Illness}

Copeman (1943) has pointed out that tender spots may persist in the muscles after such illnesses as respiratory tract infections, later to assume abnormal activity as fibrositic lesions. This calls to mind the transient bodily pains in influenza and other infectious diseases, which may persist into convalescence as fibrositis. Copeman (1944) further described some cases of multiple fibrositis in the desert (in reality they amounted to mild rheumatic fever), in which the precipitating cause was exhaustion, exposure, furunculosis, malaria, sand-fly fever, dysentery, and other non-streptococcal infections. In the pandemic of rubella of 1940 , multiple fibrositic or polyarthritic lesions were a common sequel. Case 4 is an example.

CASE 4

Mrs. L. F. had pains in her hands, knees, and ankles after German measles. The hands were swollen and the fingers stiff. The ankles were tender and slightly puffy; the site of swelling, which was mainly periarticular, was in the knees, the right being worse than the left. After a week, careful examination of the right knee revealed: (1) stiffness of the joint, which could not be flexed more than 80 degrees; (2) deep tenderness posteriorly, spreading over the lower third of the thigh and the upper third of the calf, and extending forward over the inner aspect, to the inner half of the anterior aspect of the joint; (3) swelling, mainly periarticular, in front and on the inner aspect of the joint, with some induration over the internal condyle; (4) a spot of acute tenderness was detected at the upper border of this indurated area (Fig. 6). A deep infiltration here caused all the tenderness to disappear, and the knee could be flexed fully. No more pain was felt in the knee, and the swelling subsided within 24 hours; but the joints which had not been treated remained painful and swollen for a week.

Case 4 was significant, for it demonstrated that a soft-tissue lesion could be responsible for acute rheumatic arthritis of the knee. The lesion was situated at the common "site of election" for the knee, as reported in a previous paper (Kelly, 1944a). Case 4 presented all the features of mild rheumatic fever; and one is reminded that Copeman, in his study of rheumatic fever in the desert, frequently observed painful swelling of joints to spread from fibrositic lesions in adjacent structures.

Do these cases, it will be asked, fit in with the neural theory of fibrositis? Yes, for the painful
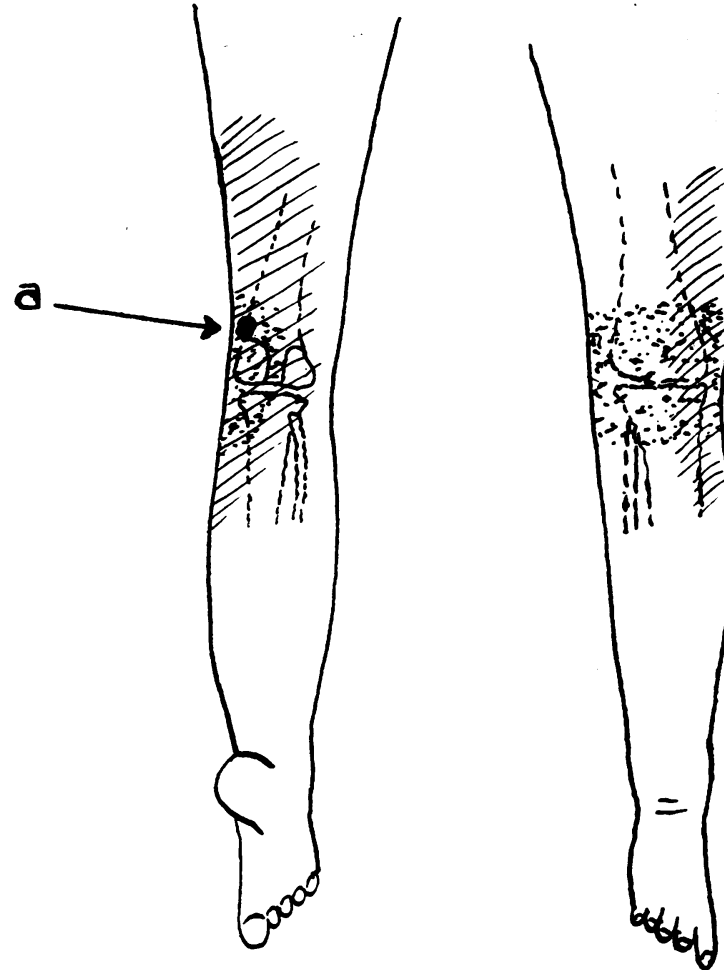

FIG. 6.-Case 4. A=myalgic lesion. Stipple=periarticular swelling. Hatching=deep tenderness which disappeared upon the injection of procaine into $\mathbf{A}$.

sequelae of infectious diseases amount only to a persistence of the bodily pains which normally accompany influenza and other fevers. And all the general signs and symptoms of infection (fever, sweating, twitching, headache, stupor, etc.) are the result of the action of the toxin upon the central nervous system. The somatic pains, it must, therefore, be agreed, also proceed from a disturbance of the nervous system. It may be suggested, on the other hand, that the toxin gives rise to the pains by affecting directly the tissues of the body. This, I think, is the generally accepted view; but there is no reason why scattered bodily pains should not be regarded as a neurological symptom rather than a somatic one. With the strictly anatomical view usually taken of the nervous system, pains are seldom regarded as symptomatic of nervous disease unless they are confined to the fields of particular nerve trunks or dermatomes; for vague and wandering pains local causes only are sought.

The more recent views upon the deep pain system and its reflex activities have provided a basis upon which bodily pains can take their place as symptoms of nervous disorders. Pain anywhere in the body may be the result of abnormal reflex activity in the deep pain system, transmitted antidromically to the periphery. We have no positive evidence that bacterial toxins can directly affect the muscles in such a way as to cause pain, while we know that the nervous system is the intermediary in the genesis of all the remaining manifestations of fever. The painful lesions which accompany fever, therefore, 
must result from enhanced activity in the deep pain system; and their spread and their persistence as fibrositic lesions (potential or actual) also must proceed from increased reflex activity in the neuronal pool (see Fig. 5). The increase of excitation in the pool of neurones causes changes in the tissues with which these neurones have functional connexion. And these tissues influence other tissues, and their persistence tends to increase the excitation in the cord; and so on.

\section{Psychosomatic Rheumatism}

Poynton (1936) suggested that a great advance in medicine would be announced if it could be proven that rheumatoid arthritis was a disease of the central nervous system. Rheumatoid arthritis, it is well known, sometimes follows nervous stress due to grief, anxiety, or exhaustion. Poynton and Schlesinger (1937) and Hubble (1943) have contended that in many cases of juvenile rheumatism, apart from chorea, there is evidence of a direct effect on the central nervous system. Hubble is not enamoured of the vague fashion in which many writers allude to the functional nervous aspect of some diseases; "to write and talk of "psychosomatic ' disorders", he said, " is to assume a bridge whose existence we but dimly discern and of whose nature we are ignorant". In a previous paper (Kelly, 1944b) the present writer has attempted to provide such a bridge between so-called " psychogenic" fibrositis and the nervous upset which might have had a share in precipitating it. If it seems certain that mental depression or nervous exhaustion has been responsible for fibrositic pains, it is not necessary to assume that the pains are hysterical or imagined. Many instances have been recorded in which profound rheumatic disease followed organic disease of the central nervous system; and it is equally easy to believe that minor rheumatic pains could be precipitated by a more transient disorder of the nervous system.

When the nervous system is deranged through anxiety or exhaustion, it is likely that its reflex activity may be enhanced so that baneful influences, which otherwise would have been ineffective, may be brought to bear upon the somatic tissues and give rise to fibrositic pain (see Fig. 5). The nervous disorder which precedes rheumatism, in fact, acts as a precipitating cause in the same way as an injury acts as a precipitating cause; i.e. by increasing the reflex activity of the centres responsible for the propagation of the disorder.

\section{The Relation of Fibrositis to Rheumatism in General}

The present fashion of dividing up the rheumatic group into distinct " disease entities" is a bar to progress in knowledge. Thus we often read of the need for accurate diagnosis of rheumatic diseases; but to me too great an insistence upon diagnosis and classification savours of putting the cart before the horse. Little indeed is known about the causes of rheumatism, or about the underlying pathological processes upon which the tissue reactions rest; yet we are asked to accept the necessity for a rigid classification of this vast amorphous group into a series of "entities" which cannot but be artificial. The layman's conception of rheumatism rests upon a broad anatomical basis, and medical science deceives itself if it imagines that it is able as yet to provide any more refined standards. The most diverse types of somatic ills, from sciatica and olecranon bursitis to rheumatoid arthritis, are called rheumatic, and we know there must be some relationship between them because we may see them occurring simultaneously in the same patient. The discovery of a key or common denominator will do a great deal towards converting chaos into order; and it is suggested that this key is provided by the fibrositic lesion.

Fibrositis has been portrayed here as a pathological rather than as a nosological concept; as a special kind of reaction in mesoblastic tissue, brought on by a number of different causes (known and unknown), rather than as a distinct " disease entity". In the early and transient cases, the pain may not be accompanied by any structural change in the tissues. In more advanced cases, changes recognizable as those of rheumatic disease occur. Acute lesions are characterized by a fibrositic reaction (or multiplication of connective-tissue cells with reversion to an embryonic type) accompanied by oedema. In the chronic cases this reaction becomes overshadowed by the process of repair, the formation of new fibrous tissue.

The fibrositic lesion, said Stockman $(1904,1911)$, is the basic unit of rheumatic disease. The fibrositic reaction, he said, may occur in any mesoblastic tissue; it produces special effects in the joints only because of the more differentiated tissues which are involved. Poynton and Schlesinger (1937) observed that soft tissue lesions occurred in all cases of rheumatic fever and rheumatoid arthritis. It is well known, too, that even advanced osteo-arthritic changes may be painless; the occurrence of pain often depends on the presence of muscular lesions. Arthritis represents only the effects of fibrositis upon the structures of a joint. But joints appear to possess a special affinity for the rheumatic process; and the reasons are clear:

1. The Radiation of Pain.--Kellgren (1938) commented frequently upon the curious fact that the pain from artificial deep lesions in the limbs tends to radiate to the joints. This is supported by clinical experience, which readily recalls the occurrepce of unexplained "arthralgias" in febrile diseases, serum sickness, caisson disease, etc. The present writer frequently has observed the pain and tenderness of a joint to vanish upon the injection of procaine into a myalgic lesion.

2. The Concentration of Mesoblastic Structures.All the structures of a joint are mesoblastic in origin. (a) The joint capsules, periosteum, and tendinous attachments are composed of adult fibrous tissue. (b) In the synovial membrane the cells are more rounded and more numerous, and 
have assumed a secretory function. When disturbed they will proliferate freely and secrete an excess of fluid. (c) Cartilage cells also are fibroblasts which have differentiated. At the junction of cartilage with synovial membrane, intermediate types develop and the cartilage cells shade off almost imperceptibly into synovial cells (Maximow and Bloom, 1934). (d) Bone cells are connective cells with special qualities. In inflammatory states they may tend to " revert to type", and decalcification results.

3. Vascular and Nervous Supply.-The synovial membrane is freely supplied with blood vessels and nerves (Gardner, 1942, 1944). The vascular tissues, being mesoblastic, share the common affinity for the rheumatic agent. Fine nerve fibres (probably the pain-plexus) ramify freely both in the adventitious coats of the vessels and in the synovial membrane itself.

4. Movement.-The synovial and supporting structures of a joint are subject to a much greater degree of mechanical strain than are the fascial and intermuscular planes. When a joint becomes involved in an acute rheumatic process, its recovery depends to a large extent upon the amount of rest that can be secured. The secretory function of the synovial cells becomes exaggerated, and further damage is caused by movement. Thus a vicious circle comes into operation, which can be broken only by assuring rest to the joint. The inflamed and proliferating cells become further deranged if subjected to mechanical strain.

The manifestations of arthritis, if the reflex hypothesis is true, represent trophic nervous effects. Proliferative and degenerative changes take place side by side, conditioned by abnormal nervous stimuli which cause the normal functions of the tissues to become deranged.

\section{Neuropathic Joints}

Charcot's joint is a familiar example of the effect of deranged nervous influences upon mesenchymal tissue. The destructive and explosive changes are but an exaggeration of the effects seen in other forms of arthritis (King, 1930; Knaggs, 1932); and their special character is due to the abnormal nervous supply to the tissues. Once the Charcot joint was regarded as a thing apart-a special form of arthritis with no relation to the milder and multiple forms seen in osteo-arthritis and rheumatoid arthritis. In reality, however, it represents but the most advanced stage of arthritis, in which the effects of abnormal neural influences are most apparent. The neuropathic joint is the exception which proves the rule; it exemplifies and emphasizes the important part played by nerve impulses in the larger group of rheumatic disorders.

\section{An Earlier Neural Theory of Rheumatic Disease}

A nervous theory of rheumatism which flourished last century had its origin 100 years previously in the "vitalistic" hypothesis of disease embraced by
Stahl and Hoffmann, and by William Cullen of Edinburgh. Professor J. K. Mitchell (1831), the father of the more illustrious Weir Mitchell, wrote of the spinal cord as the seat of rheumatism, which he held to be a manifestation of the disordered activity of nervous tissue. Paget came to give strong support to the theory; and both Weir Mitchell (1872) and Charcot (1877) contended that the trophic nerves to the joints were responsible for the manifestations of arthritis. This view was adopted by the majority of the leading physicians of the latter half of last century, including the Edinburgh teachers Laycock (1864) and Liveing (1873), and Ord (1880) Duckworth (1880) and Latham (1886) of London, and many others. The theory was sent into oblivion by the triumphant onrush of bacteriology, assisted by the sledgehammer blows of Maclagan (1896), who held it up to scorn. Bacteriology, however, has failed to solve the problem of the nature of rheumatic disease. During the past few years more attention has been given to the part played by the nervous supply in the nutrition of tissues. Plewes (1940) and L. C. Kelly (1943) have given good reasons for regarding osteoarthritis of the hip as a trophic disorder, while Kelikian (1943) contends that neural influences are responsible in many other instances of chronic arthritis. Pemberton and Scull (1943) and Stone (1943) regard the polyarthritic syndromes as manifestations of underlying central disorders.

The important part played by nervous influences in ensuring the orderly functioning of tissues, so clearly obvious to the clinicians of last century, is almost forgotten to-day. There seems to be a mystic quality about such a view that records ill with our present fashions, which prefer to seek for bacteriological, biochemical, or mechanical causes for our ills. Many, indeed, are forgetful of the unseen neural control which co-ordinates all the activities of living tissues. When separated from nervous control, muscles fibrillate and waste away, squamous epithelium becomes thin and shiny, subcutaneous tissues atrophy, and fat loses its structure. The delicately integrated mechanisms of the nervous system keep watch over every part of the body, so that each tissue preserves its normal function and its normal structure. In rheumatism, influences from within or form without have disturbed that balance, and the loss of integration is reflected in dystrophy of the tissues.

\section{Summary}

1. According to the neural theory of fibrositis, the mechanism by means of which a myalgic lesion follows an injury is the same as that by which painful spots appear in the body wall during visceral disease.

2. The process is dependent upon an increase of reflex excitation in the deep pain system.

3. The formation of multiple lesions after injury is dependent upon a spread of this excitation in the cord.

4. A like explanation holds good for the multiple 
rheumatic lesions which follow a febrile illness (e.g. rheumatic fever); and for so-called "psychogenic" rheumatism.

5. The fibrositic lesion is the basic unit of rheumatic disease, which presents characteristic appearances in joints only because of the special qualities of the articular structures.

6. Reference is made to the fact that the clinical teachers of last century generally took the view that rheumatism was a disorder of the central nervous system.

\section{REFERENCES}

Charcot, J. M. (1877). Lectures on Diseases of the Nervous System. London. New Sydenham Society.

Copeman, W. S. C. (1943). Annals of the Rheumatic Diseases, 3, 222 (1944). Ibid., 4,11.

Douthwaite, A. H. (1945). Med. Annual, p. 70.

Duckworth, D. (1880). Brain, 3, 1.

Ernstene, A. C., and Kinell, J.'(1940). Arch. intern. Med., 66, 800.

Gardner, E. D. (1942). Anat. Rec., 83, 401.

(1944). J. Comp. Neurol., 80, 11.

Gasser, H. S. (1937). Harvey Lectures (1936-37), 32, 169.

Head, H., Rivers, W. H. R., and Sherren, J. (1905). Brain, 28, 99.

Hinsey, J. C., and Phillips, R. A. (1940). J. Neurophysiol., 3, 175.

Hubble, D. (1943). Brit. med. J., 1, 121, 154.

Kelikian, H. (1943). Surg. Gynec. Obstet., 76, 469

Kellgren, J. H. (1938). Clin. Sci., 3, 175.

Kellgren, J. H. (1938). 35.

Kelly, L. C. (1943). Ohio State med. J., 39, 26.
Kelly, M. (1944a). Med. J. Austral., 1, 286.

(1944b). Annals of the Rheumatic Diseases, 4, 46.

(1945). Ibid., 5, 1.

- (1946). Ibid., 5, 69

King, E. S. J. (1930). Brit. J. Surg., 18, 113.

Knaggs, R. L. (1932). Ibid., 20, 113, 309.

(1933). Ibid., 20, 425.

Latham, P. W. (1886). Lancet, 1, 626, 673, 723, 771, and 817.

Laycock, $T$. (1864). The Principles and Methods of Medical Observation and Research. Edinburgh. 2nd ed., Maclachlan and Stewart.

Lewis, T. (1942). Pain. New York. Macmillan.

and Kellgren, J. H. (1939). Clin. Sci., 4, 47.

Liveing, E. (1873). On Megrim, Sick Headache, and Some Allied

Disorders. London. Churchill.
Livingston, W. K.(1943). Pain Mechanisms. New York. Macmillan. Mackenzie, J. (1920). Symptoms and their Interpretation. London. 4th ed. Shaw.

Maclagan, T. J. (1896). Rheumatism; its Nature, its Pathology, and its successful Treatment. London. Black.

Maximow, A. A., and Bloom, W. (1934). Text-Book of Histology. Philadelphia. 3rd ed. Saunders.

Mitchell, J. K. (1831). Amer. J. med. Sci., 8, 55. (Cited by Latham.)

Mitchell, S. Weir (1872). Injuries of Nerves and their Consequences. Philadelphia. Lippincott.

Ord, W. M. (1880). Brit. med. J., 1, 155.

Ord, W. M. (1880). Brit. med. J., 1, 155. J. (1879). Clinical
Longmans, p. 431.

Pemberton, R., and Sculi, C. W. (1943). Ann. intern. Med., 19, 482.

Plewes, L. W. (1940). Brit. J. Surg., $27,682$.

Poynton, F. J. (1936). J. State Med., 44, 349.

and Schlesinger, B. (1937). Recent Advances in the Study of Rheumatism. London. 2nd ed. Churchill.

Seddon, H. J. (1943). Brain, 66, 237.

Sharpey-Schäfer, E. (1927). Ibid., 50, 538.

Stockman, R. (1904). Edinb. med. J., 15, 107, 223.

(1911). Brit. med. J., 1, 352.

Stone, S. (1943). J. nerv. ment. Dis., 97, 638.

Trotter, W., and Davies, H. M. (1909). J. Physiol., 38, 134.

\section{EPILOGUE TO THE SERIES ENTITLED "THE NATURE OF FIBROSITIS"}

\section{MICHAEL KELLY}

No claim is made that a new hypothesis has been propounded, for a neural theory of rheumatism is two hundred years old. The present observations represent merely the collected observations of many others, perhaps co-ordinated a little and brought up to date with modern neurophysiology. Plenty of corroborative evidence is to hand in the literature, did one but take the trouble to collect it.

No claim is made, either, that the "cause" of rheumatism has been discovered; rather is it suggested that the mechanism has been traced through which the various causes bring about their endresults. There is no single cause for this group of diseases; more likely it is the result of a number of causes, which in different cases may be different, though perhaps acting through the same mechanism. To the casual glance a stiff neck does not resemble rheumatoid arthritis; but neither does a furuncle resemble chronic osteomyelitis, and in the days before Lister it would not have been easy to believe that they were due to the same cause. By agreeing to speak of " rheumatism ", we all display our belief in the basic unity of rheumatic disease; but, with no clear view of its essential nature, we are forced to divide it up into a number of separate " entities", which may prove to be as closely linked to each other as the various staphylococcal infections are linked to each other.

The proposed theory, it is feared, has not dramatic appeal enough to shake the old-established beliefs even in their present confused state. It demands a retracing of the steps over some sixty years, and the discarding of much that we have been taught to accept as self-evident. Even supposing it to be true, many may wonder if it is useful, because it opens up no royal road to the prevention or the cure of rheumatic disease. The answer, of course, is that the truth should be sought at all costs, for itself alone. If the theory is proven to be erroneous, no harm will have been done, for it has been well said that truth is more likely to emerge from error than from confusion.

It has been wisely stated, also, that the value of hypothesis lies not so much in the ingenuity of invention as in the labour of verification. The verification of this hypothesis depends upon the painstaking and careful observation of mild and transient cases of somatic pain, and of early cases of rheumatic disease. Rheumatism clinics rarely see such common affections as the transient spreading pains which sometimes follow mild injuries or infections; and these, perhaps, could throw a good deal of light upon the mechanism of the rheumatic process. They usually remain in the hands of the general practitioner; there can be little doubt, therefore, that the observant general practitioner holds the key to the situation. 